Exploring children's perceptions of the perceived seriousness of disruptive classroom behaviours

Louise Dursley \& Lucy R. Betts

Division of Psychology, Nottingham Trent University, UK

Corresponding author: Lucy R. Betts, Division of Psychology, Nottingham Trent University, Burton Street Nottingham, NG1 4BU. Email lucy.betts@ntu.ac.uk Ph +44 (0) 1158485558 


\begin{abstract}
Children's reports of the perceived seriousness of disruptive classroom behaviours were examined from their own perspective and from their perceptions of their peers' beliefs about the same behaviour. Two hundred and 76 (116 female and 161 male, $M_{\mathrm{age}}=11.00$ years, $\left.S D_{\text {age }}=1.29\right)$ children recruited from a primary and a secondary school in the UK completed measures of the perceived seriousness of disruptive classroom behaviours from their own perspective and also their beliefs about their peers' perceptions, social desirability, and social behaviour. A three factor structure of disruptive classroom behaviours emerged encompassing: Imprudent behaviours, negative behaviours, and expressed emotions. Children judged the disruptive classroom behaviours as more serious compared to how they thought their peers would judge the same behaviour. Gender and age differences also emerged. The findings support the conclusion that children regard disruptive classroom behaviours as more serious than they believe their peers do.
\end{abstract}

Key words: disruptive classroom behaviours, social desirability, social behaviour, self-reports 


\section{Exploring children's perceptions of the perceived seriousness of disruptive classroom}

\section{behaviours}

Concerns surrounding the long-term outcomes of antisocial behaviour in the classroom for both children and teachers (Ford et al., 2012), have prompted a number of researchers to propose a range of techniques designed to reduce antisocial behaviour in schools (e.g., Abbott et al., 1998; Patterson, Reid, Jones, \& Conger, 1975). Despite some success in reducing antisocial behaviour in schools, through these various interventions, research indicates that a child's propensity to behave antisocially at school emerges during primary school (Offord, Boyle, Fleming, Blum, \& Grant, 1989; Waschbusch, Porter, Normand, Omar, \& D’Amico, 2004) and then develops through adolescence (Loeber \& Dishion, 1983), and into adulthood (Loeber, 1990). In classrooms with high levels of antisocial behaviour, and where positive behaviour receives less recognition, engagement in antisocial behaviour is likely reinforced by peers and, as such, perpetuated. This perpetuation of antisocial behaviour may ultimately result in reduced engagement with school (Ford et al., 2012), poorer teacher-child relationships (Buyse, Verschueren, Doumen, van Damme, \& Maes, 2008), and burnout in teachers (Otero López et al., 2008). Further, children's antisocial behaviour constitutes one form of low level disruption frequently encountered by teachers in the classroom that can negatively impact on children's cooperation in the classroom and their propensity to learn (Esturgó-Deu \& Sala-Roca, 2010; Kramer, Davies, Arndt, \& Hunley, 2012).

Whilst studies have developed measures to examine teachers' perceptions of antisocial behaviour and low level disruption in the classroom, how serious 9- to 13-year-olds regard low level disruptive classroom behaviour remains unclear. Therefore, the present study addressed this issue by developing the existing perceived seriousness of pupils' undesirable behaviours scale (Kokkinos, Panayiotou, \& Davazoglou, 2004) such that it was appropriate 
for children to provide self-reports of the perceived seriousness of disruptive behaviours rather than student teachers as in the original study by Kokkinos et al.

Undesirable behaviour and low level disruptive behaviours have been conceptualised as a multifaceted set of actions (Poulin \& Boivin, 2000) including bullying behaviours such as temper tantrums, hitting and throwing, and non-compliance characterised by a disregard for authority (Douglas, 1988). More recently, the definition has been extended to include verbal abuse, dirty looks, physical abuse, intent to cause injury, rejection, stealing friends, and delinquency (Warden, Cheyne, Christie, Fitzpatrick, \& Reid, 2003). Further, low level disruptive behaviour is typically teacher-centred (Hall \& Hayden, 2007) and includes behaviours such as shouting, talking loudly, calling out, and distracting the teacher which prevent the teacher from teaching and other children from learning (Swinson, 2010). Consequently, low level disruptive behaviours in the context of the classroom can be considered to be those behaviours which cause disturbance to the rest of the class, either through noise, inappropriate use of language, bullying behaviours, or damage to the schools' or other classmates' belongings.

Previous research has examined teachers' perceptions of student behaviours (Borg \& Falzon, 1989; Stuart, 1994), as well as their judgements of the seriousness of school behaviour in relation to children's gender (Kokkinos et al., 2004). However, whilst it is widely accepted that the severity of disruptive behaviour varies, relatively few studies have examined children's perceptions of the seriousness of disruptive behaviours but those that have, have reported differences between students' and teachers' perceptions. For example, high school students in Turkey report experiencing less misbehaviour in school and are less disturbed by such behaviour than their teachers (Burgaz \& Ekinci, 2007). Similarly, Mitchell, Bradshaw, and Leaf (2010) reported variations in teachers' and fifth-grade children's perceptions of classroom climate and suggested that teachers may be more sensitive to 
classroom factors than children. Together, these studies provide some evidence that children and teachers differ in their perceptions of the seriousness of disruptive classroom behaviours.

Examining children's perceptions of the seriousness of disruptive classroom behaviours may afford researchers a greater insight into children's beliefs about classroom behaviours and the reasons why children may engage in such behaviour. Although multiple informants such as teacher reports and peer reports have been used to assess behaviour (e.g., Veenstra et al., 2008), the extent to which such reports accurately capture an individual's experience can be questioned. Similarly, observational techniques designed to assess behaviour can be prone to subjective interpretations and also constrained by environmental restrictions (Crick \& Grotpeter, 1995). Further, a lack of consideration into an individual's insight merely limits the research field from acquiring further understanding from children's own experiences (Warden et al., 2003). Moreover, children maybe in the best position to identify their own internal states, and together may help in uncovering potential underlying reasons behind their actions.

Children's peers represent major socialisation agents across development that are important for future relationship formation (Thelen \& Smith, 1998) and psychosocial adjustment (Patterson, Vaden, Griesler, \& Kupersmidt, 1991; Rubin, Bukowski \& Parker, 1998). Experiencing deviant peer socialisation enhances the propensity with which a child engages in aggressive behaviour (Cairns, Cairns, \& Neckerman, 1989; Coie, Dodge, Terry, \& Wright, 1991; Hymel, Comfort, Schonert-Reichl, \& McDougall, 1996) either as a defense mechanism (Coie \& Kupersmidt, 1983) or because of anxiety due to a perceived lack of control over the environment (Connor, 2002). Therefore, children may come to regard the severity of disruptive classroom behaviours as similar to how their peers consider the same behaviour (Corsaro \& Eder, 1990). Further, children may also use their knowledge of their peers' responses to particular behaviours as a guide to inform their own future actions 
(Armstrong, 2011). Consequently, the present study also examined: (a) children's perceptions of the seriousness with which they believe their peers regard disruptive classroom behaviour and (b) the differences between children's self-reported perceptions of the seriousness of disruptive classroom behaviour and children's reports of their peers' perceptions of the seriousness of disruptive classroom behaviour.

The current study also examined age differences in the children's self-reports and reports concerning their peers' perceived seriousness of disruptive classroom behaviour according to whether the children attended primary school or secondary school. Examining age differences according to the school the children attended is appropriate because it reflects changes in moral development (Lahat, Helwig, \& Zelazoc, 2012), cognitive development, and maturity that occur during the transition to secondary school (Smith \& Hart, 2002). Whilst there is some evidence that antisocial behaviour is stable (e.g., Dishion, Patterson, Stoolmiller, \& Skinner, 1991; Tremblay et al., 1991), some studies have reported that older boys are typically more disruptive than younger boys (e.g., Lahey, Miller, Gordon, \& Riley, 1999; Loeber \& Keenan, 1994; Loeber \& Southeramer-Loeber, 1998; Waschbusch et al., 2004). Further, older children also tend to engage in less on-task classroom behaviour and report greater difficulties in identifying the relevance of school work than younger children (Bru, 2006). However, as children age they become more aware of the socially appropriate and socially desirable ways to behave (Tremblay, 2010) and, as such, antisocial behaviour may decrease with age.

Gender differences in the children's responses to their own perceptions of the seriousness of disruptive classroom behaviours and those of their peers were also examined. Previous research has indicated that complex gender differences occur with regard to aggressive behaviour of boys and girls with differences emerging according to type of aggression (Estell, Farmer, Pearl, van Acker, \& Rodin, 2008). However, 6- to 12-year-old 
boys engaged in more disruptive classroom behaviours than girls (Esturgó-Deu \& Sala-Roca, 2010) and, as such, may regard the seriousness of such behaviour differently.

Whilst children are often aware of disruptive classroom behaviours this does not necessarily mean that they consider engaging in such as undesirable or disruptive to others (Cuddy \& Frame, 1991; Huesmann \& Guerra, 1997; Perry, Perry, \& Rasmussen, 1986; Slaby \& Gueera, 1988). In particular, some children have a greater propensity to engage in socially desirable behaviour because they believe it is regarded favourably by their peers (Hennessy, Swords, \& Heary, 2008; Juvonen, 1991) whereas other children are more supportive of aggressive behaviour because they believe such behaviour yields positive results (Perry et al., 1986; Slaby \& Guerra, 1988). Therefore, to test the concurrent validity of the revised versions of perceived seriousness of pupils' disruptive behaviour scales, the association between the scale scores and self-reported social behaviour and propensity to engage in socially desirable behaviour were examined.

The current study developed two versions of the revised perceived seriousness of pupils' undesirable behaviour scale (Kokkinos et al., 2004) to examine children's perceptions of: (a) the seriousness of their own disruptive classroom behaviour and (b) their peers' perceptions of the seriousness of disruptive classroom behaviour and to investigate potential differences in these perceptions. The associations between these two measures and children's self-reported social behaviour and social desirability were examined as evidence of the convergent validity of the newly developed scales. Age and gender differences were also examined.

\section{Method}

\section{Participants}

Two hundred and 76 (116 female and 161 male) participants were recruited from a primary school $\left(133\right.$ children, $M_{\text {age }}=9.92$ years, $\left.S D_{\text {age }}=.72\right)$ and a secondary school $(143$ 
children $M_{\text {age }}=11.98$ years, $\left.S D_{\text {age }}=.77\right)$ in the UK. Participants at the primary school were aged between 9 and 11 and participants at the secondary school were aged between 11 and 13 . Both schools had urban catchment areas: One school was a state school and the other was private. Two classrooms for each year from each school participated.

\section{Measures}

Perceived seriousness of disruptive classroom behaviours. The 25 item perceived seriousness of pupils' undesirable behaviour scale (Kokkinos et al., 2004) was originally developed to assess student teachers' perceptions of the seriousness of pupils' undesirable behaviours. In the current study, the participants completed 24 of the original items twice according to: (1) how serious they thought each of the behaviours were and (2) how serious they thought their peers would regard the behaviours using a 5-point scale ranging from 1 (Not at all serious) to 5 (Extremely serious). The wording of some of the items was modified to ensure that they were suitable for the age of the sample.

Social behaviour. Participants also completed 37 items from the social behaviour questionnaire (Tremblay et al., 1991) to indicate their self-reported social behaviour conceptualised as disruptiveness, physical aggression, anxiety, inattention, hyperactivity, opposition, and prosociality using a 5-point scale ranging from 1 (Never) to 5 (Always). Items were recoded such that higher scores indicated a greater self-reported propensity to engage in negative social behaviour (e.g., "Behaves badly"). The scale demonstrated acceptable internal consistency $(\alpha=.85)$. Previous research has demonstrated the reliability and validity of the scale (e.g., Luteijn, Lutejin, Jackson, Volkmar, \& Minderaa, 2000).

Social desirability. The 12-item short-form A of Crandall's social desirability questionnaire (Carifio, 1994) was administered to participants to indicate their propensity to engage in socially desirable behaviour. Participants completed the items by indicating whether each statement applied to them (e.g., "I am always polite to older people") using a 
True / False response format. The items were coded such that a higher score indicated a greater propensity to engage in socially desirable behaviour. Carifio (1994) reported that the short-form scale had high levels of internal consistency and construct validity. In the current study, removing one item from the scale yielded an acceptable internal consistency for the scale $(\alpha=.71)$. The shortened version of the scale was used in all subsequent analysis.

\section{Procedure}

The questionnaires were administered to the children in a classroom setting whilst the researcher read out the instructions and items as the children completed them. The researcher provided support to the children as appropriate. The children were instructed to complete the questionnaires independently, that it was not a test, and that there were no correct answers. Consent for the research was initially gained from the head teachers at the participating schools and parents were informed of the nature of the study by letter and asked to indicate if they did not want their son / daughter to participate. No parents returned the forms. The children also gave their assent before data collection commenced and two children declined to participate.

\section{Results}

\section{Item analyses}

To ensure that the items for both scales generated a range of responses, the facility indexes were examined. The facility indexes revealed that for both scales the items generated a range of responses and, as such, were retained for subsequent analyses (Rust \& Golombok, 1999). Following Rust and Golombok's recommendations, the corrected item-total correlations were also examined for both scales to ensure that the items had positive correlation coefficients greater than .20: All of the items did and consequently were retained for subsequent analyses. 


\section{Factor analyses}

Exploratory factor analyses using principal axis factoring as the extraction method were conducted to separately examine the factor structure of the two scales: (a) self-reports of the perceived seriousness of disruptive classroom behaviours and (b) the perception of peers' perceived seriousness of disruptive classroom behaviours. The exploratory factor analyses were followed by oblimin rotations because the scale items were designed to assess the overall constructs of disruptive classroom behaviours (Field, 2002; Tabachnick \& Fidell, 2001). Exploratory factor analyses and oblimin rotations were used in preference to confirmatory techniques because Kokkinos et al. (2004) reported that, in the original version of the scale, many items loaded on more than one factor.

The initial factor structure for the self-perceptions of perceived seriousness of disruptive classroom behaviour identified eight items that loaded on multiple factors and, as such, were removed and the analysis repeated (Fabrigar, Wegener, MacCallum, \& Strahan, 1999). The final factor structure for the self-perceptions of perceived seriousness of disruptive classroom behaviour accounted for $61.45 \%$ of the variance (see Table 1 for item loadings). Based on the item loadings the factors were labelled as imprudent behaviours, negative behaviours, and expressed emotions. The analysis was repeated for children's believes about how their peers perceived the seriousness of disruptive classroom behaviour and the final solution accounted for $67.04 \%$ of the variance (see Table 1 for item loadings). The same three factor structure emerged as for the self-perceptions and, as such, the factors were again labelled as imprudent behaviours, negative behaviours, and expressed emotions. All of the extracted factors had Eigenvalues $>1$.

Insert Table 1 about here 
The internal consistency for all of the subscales across both versions were good, $\alpha=\geq$ .84 and $\leq .90$.

\section{Associations with social behaviour and social desirability}

Concurrent validity of the two revised perceived seriousness of disruptive classroom behaviour scales was examined through the association between the subscale scores, social behaviour scores, and social desirability using partial correlations, controlling for age (Table 2). There were small positive associations between the various subscales of the perceived seriousness of disruptive classroom behaviour indicating the more serious one form of behaviour was considered the more serious the other forms were. Further, children who perceived the behaviours as more disruptive also reported that their peers would perceive the same behaviours as more disruptive. Negative associations also emerged between the perceived seriousness of disruptive classroom behaviour and social behaviour: Children who rated disruptive classroom behaviour as more serious reported engaging in less negative behaviour. Social desirability was positively associated with self-perceptions of the seriousness of imprudent behaviours and peer perceptions of the seriousness of imprudent behaviours and expressed emotions: Greater reported social desirability was associated with greater reported seriousness of these behaviours.

Insert Table 2 about here

\section{Differences between self-perceptions and reported peer-perceptions}

To examine whether differences emerged between children's self-reported perceptions of the perceived seriousness of disruptive classroom behaviours and the children's reports of their peers' perceptions of the seriousness of disruptive classroom behaviours a series of paired samples t tests were performed for each of the three subscales. Children reported that they perceived imprudent behaviours, $t(274)=4.02, p<.001, d=.185 M_{\text {Self }}=14.55 S D_{\text {Self }}=$ 
4.47 $M_{\text {Peers }}=13.66 S D_{\text {Peers }}=5.11$, negative behaviours, $t(274)=6.92, p<.001, d=.327 M_{\text {Self }}$ $=19.55 S D_{\text {Self }}=4.14 M_{\text {Peers }}=18.13 S D_{\text {Peers }}=4.53$, and expressed emotions, $t(274)=3.98, p<$ $.001, d=.186 M_{\text {Self }}=14.07 S D_{\text {Self }}=4.25 M_{\text {Peers }}=13.22 S D_{\text {Peers }}=4.89$, as more serious than their peers.

\section{Age and gender differences}

A 2 x 2 (age [primary, secondary] x gender [male, female]) independent MANOVA was used to examine gender and age differences in the children's self-perceptions of the perceived seriousness of disruptive classroom behaviours. The subscale scores for imprudent behaviours, negative behaviours, and expressed emotions were entered as the dependent variables. The analysis revealed significant age differences in the children's self-perceptions of the perceived seriousness of disruptive classroom behaviour, $\Lambda=.92, F(3,269)=7.95, p<$ $.001, \eta^{2}=.081$. Subsequent ANOVAs revealed significant age differences in the children's imprudent behaviours, $F(1,271)=17.31, p<.001, \eta^{2}=.061$, and expressed emotion, $F(1,271)$ $=17.88, p<.001, \eta^{2}=.062$, subscale scores: Children at primary school reported that some disruptive classroom behaviours were more serious than children from secondary school for both imprudent behaviours, $M_{\text {Primary }}=15.70 S D_{\text {Primary }}=4.35, M_{\text {Secondary }}=13.48 S D_{\text {Secondary }}=$ 4.33 , and expressed emotion, $M_{\text {Primary }}=15.22 S D_{\text {Primary }}=4.20, M_{\text {Secondary }}=13.00 S D_{\text {Secondary }}=$ 4.03. There were no other significant age or gender differences and no significant age and gender interaction.

A 2 x 2 (age [primary, secondary] x gender [male, female]) independent MANOVA was also used to examine gender and age differences in the children's self-reports of peers' perceptions of the perceived seriousness of disruptive classroom behaviours. The subscale scores for peers' perceptions of imprudent behaviours, negative behaviours, and expressed emotions were entered as the dependent variables. The analysis revealed significant age, $\Lambda=$ $.88, F(3,269)=11.82, p<.001, \eta^{2}=.117$, and gender, $\Lambda=.96, F(3,269)=4.01, p=.008, \eta^{2}=$ 
.043 , differences in the children's reports of their peers' perceptions of the perceived seriousness of disruptive classroom behaviour. Subsequent ANOVAs revealed significant age differences in the children's reports of how their peers regard imprudent behaviours, $F(1,271)$ $=31.32, p<.001, \eta^{2}=.104$, negative behaviours, $F(1,271)=9.38, p=.002, \eta^{2}=.033$, and expressed emotion, $F(1,271)=26.54, p<.001, \eta^{2}=.089$, subscale scores: Children at primary school reported that their peers perceived disruptive classroom behaviours as more serious than children from secondary school for imprudent behaviours, $M_{\text {Primary }}=15.43$ $S D_{\text {Primary }}=5.22, M_{\text {Secondary }}=12.00 S D_{\text {Secondary }}=4.41$, negative behaviours, $M_{\text {Primary }}=19.13$ $S D_{\text {Primary }}=4.09, M_{\text {Secondary }}=17.20 S D_{\text {Secondary }}=4.74$, and expressed emotion, $M_{\text {Primary }}=14.84$ $S D_{\text {Primary }}=4.79, M_{\text {Secondary }}=11.71 S D_{\text {Secondary }}=4.49$. Subsequent ANOVAs also revealed significant gender differences in the children's reports of how their peers regard negative behaviours, $F(1,271)=7.83, p=.005, \eta^{2}=.028$ : Girls reported that their peers perceived negative behaviour as more serious than boys, $M_{\text {Girls }}=19.18 S D_{\text {Girls }}=4.28, M_{\text {Boys }}=17.38$ $S D_{\text {Boys }}=4.58$. There were no other significant gender differences and no significant interaction between age and gender.

To examine whether the results occurred because of systematic differences in social desirability, a 2 x 2 (age [primary, secondary] x gender [male, female]) independent ANOVA was used to test for age and gender differences in social desirability. The results revealed no significant age or gender differences and no significant age and gender interaction.

\section{Discussion}

In summary, a clear three factor structure emerged for children's: (a) self-reported perceptions of the perceived seriousness of disruptive classroom behaviour and (b) reports of their peers' perceptions of the perceived seriousness of disruptive classroom behaviour. The three factors comprised: Imprudent behaviours, negative behaviours, and expressed emotion. There was also some evidence that the perceived seriousness of disruptive classroom 
behaviour was associated with social desirability and social behaviour. Differences also emerged according to how serious children perceived disruptive classroom behaviour and how serious they believed their peers regarded the same behaviour. Finally, some age and gender differences also emerged in the children's self-perceptions of disruptive classroom behaviours and their reports of their peers' perceptions of the seriousness of disruptive classroom behaviours.

The imprudent behaviours, negative behaviours, and expressed emotions subscales comprised the same items for both versions of the scale. However, the factor structure identified in the current study differed from that originally reported by Kokkinos et al. (2004) when the scale was administered to student teachers. There was also some difference in the relative strength of the item loadings which reflects that different perceptions of disruptive classroom behaviours may emerge across these various groups (Hartup, 1979; Rutter \& Taylor, 2001). In further support of this argument, children regarded the disruptive classroom behaviours as more serious when they were asked to complete the scale from their own perspective compared to when they were asked to complete the scale from the perspective of their peers. There are a number of potential explanations for this finding. First, children's reports that they perceive disruptive classroom behaviour as more serious than their peers can be accounted for by the better than average effect: The tendency to see one's own behaviour as more positive than others (Brown, 2012). Second, children may recognise the importance of their peers as informants of social behaviour (Furman \& Buhrmester, 1992; Harrist, Pettit, Dodge, \& Bates, 1994). Third, the results may reflect children's knowledge that such behaviours are often regarded as inappropriate (Eagly, \& Chaiken, 1993). Children may also repress the desire to act externally but rather internalise the experiences of observing the behaviour. However, the current findings contradict Corsasro and Eder's (1990) suggestions as children regarded disruptive classroom behaviours as more serious than they thought their 
peers would. Whilst differences emerged between the children's reports of the perceived seriousness of disruptive classroom behaviour from the children's own perspectives and how children thought their peers would regard the same behaviour, there were strong associations between the various subscales. One potential explanation for these associations is that children are influenced by their peers' behaviour and use this to validate and assess their own behaviour (Brown, 2012).

As expected, and as evidence of the convergent validity, the children's reports of the perceived seriousness of the disruptive classroom behaviours were associated with their social behaviour: Children who regarded disruptive classroom behaviour as more serious engaged in more positive behaviour. This finding is similar to previous studies that have highlighted a link between how behaviour is perceived by adolescents and the frequency with which they engage in the same behaviour (Perry et al., 1986; Slaby \& Guerra, 1988).

There was also evidence that children who attended secondary school regarded disruptive classroom behaviours as less serious than those younger children who attended primary school. Although the effect sizes were small this finding offers a possible explanation as to why older children are typically regarded as more disruptive than younger children (Lahey, Miller, Gordon, \& Riley, 1999; Loeber \& Keenan, 1994; Loeber \& Southeramer-Loeber, 1998; Waschbusch et al., 2004). Specifically, because younger children regard classroom disruptive behaviour as more serious than older children they may engage in that behaviour less frequently and, as such, engage in more on-task classroom behaviour (Bru, 2006). Alternatively, as children get older the disruptive classroom behaviours may have become more frequent and more visible to others which may in turn increase the acceptability of these behaviours as normative. Future research is needed to further examine this link and also to explore whether the children's self-reports of the perceived seriousness of disruptive classroom behaviour translates in to their classroom behaviours. Additionally, the evidence of 
an association between attitudes and behaviour is mixed (Eagly \& Chaiken, 1993) with other factors such as social norms and the visibility and involvement of peers (Brown, Clasen \& Eicher, 1986; Tremblay, Pihl, Vitaro \& Dobkin, 1994; Laird, Pettit, Dodge \& Bates, 1999; Smith \& Hart, 2002) impacting on the association between attitudes and behaviour.

Although previous research has reported that gender differences occur in children's aggressive behaviour (Estell et al., 2008), the current study found only limited evidence of gender differences. The only gender difference that emerged was for girls' reports of their peers' perceptions of the seriousness of negative behaviour which was regarded as significantly more serious than boys. One potential explanation for this resides in the gender differences in children's peer networks. Specifically, girls' social networks tend to be characterised by intimacy whereas boys' social networks tend to be more activity orientated (Erwin, 1995). Therefore, for girls negative behaviours may be particularly disruptive for their networks and, as such, they may believe that their peers regard these behaviours negatively because they place such value on their peer networks. Further, previous research has reported that girls are more inclined to engage in relational aggression, whereas boys tend to engage in overt aggression (Crick, Bigbee, \& Howes, 1996; Lagerspetz, Bjőrkqvist, \& Peltonen, 1988; Little, Henrich, Jones \& Hawley, 2003) and, as such, these differences may reflect the perceived seriousness of disruptive classroom behaviours. Specifically, girls may rate physical aggression as more severe due to perceptual differences in the nature and purpose of the behaviour (Geen, 2001). Alternatively, girls may regard disruptive classroom behaviour as more serious because they are less likely to engage in such behaviours.

The findings of the current study could inform future developments of interventions similar to those developed to reduce antisocial behaviour (e.g., Abbott et al., 1998; Patterson et al., 1975). For example, these interventions could be developed to include further recognition of how children regard the seriousness of disruptive classroom behaviour and how 
their perceptions of how others view the same behaviour may be different. The interventions could also be informed by the better than average effect (see Brown, 2012) as a method of trying to realign children's perceptions of the disruptive classroom behaviour. Further, by influencing the propensity to which children engage in disruptive classroom behaviour may enhance on-task classroom involvement and, in turn, bear on academic performance. The scales examined in the current study could also be used in educational settings in social and emotional aspects of learning programmes designed to promote a positive classroom environment (Humphrey, Lendrum, \& Wigelsworth, 2010). For example, the questionnaire could serve as a useful starting point when examining appropriate classroom behaviour with children. Teachers could then discuss with the children the impact of the low level disruptive behaviour for knowledge transmission (Swinson, 2010).

Whilst the factor structure of the scales developed in the current study accounted for a large proportion of the variance and the scales demonstrated acceptable validity and internal consistency, the study is not without limitations. The study only examined children's perceptions about what they believed their peers thought about the seriousness of disruptive classroom behaviour. Consequently, there could be bias in the children's reports (Crick \& Gropter, 1995) and it is not possible to determine what the peers' perceptions of the seriousness of the behaviour. Moreover, the current study did not take in to consideration whether children perceive the same behaviour differently according to the peer who enacted the behaviour. For example, the same behaviour is often interpreted differently according to the gender of the actor (Condry \& Condry, 1976). Therefore, having identified the psychometric properties of the various versions of the perceived seriousness of pupils' undesirable behaviours scale, future research could adopt a method similar to Armstrong (2011) where the parallel versions of the scale are completed by children, peers, and teachers to examine the accuracy of the children's knowledge of how their peers regard antisocial 
behaviour. Conducting such a study would be appropriate because children often use their peers as an information source to inform future behaviour (Armstrong, 2011).

In summary, the present study found evidence of differences in children's self-reported perceptions of the perceived seriousness of disruptive classroom behaviours compared to children's perceptions of their peers' reports of the perceived seriousness of the same behaviours. 


\section{References}

Abbott, R. D., O’Donnell, J., Hawkins, J. D., Hill, K. G., Kosterman, R., \& Catalano, R. F. (1998). Changing teaching practices to promote achievement and bonding to school. American Journal of Orthopsychiatry, 68, 542-552. doi: 10.1037/h0080363

Armstrong, C. (2011). The impact of self and peer perceptual differences on student social behaviour. British Journal of Educational Psychology, 81, 355-368. doi: $10.1348 / 000709910 \times 522393$

Borg, M. G., \& Falzon, J. M. (1989). Primary school teachers' perceptions of pupils' undesirable behaviours. Educational Studies, 15, 251-260. doi: $10.1080 / 0305569890150304$

Brown, B. B., Clasen, D. R., \& Eicher, S. A. (1986). Perceptions of peer pressure, peer conformity dispositions, and self-reported behaviour among adolescents. Developmental Psychology, 22, 521-530. doi: 10.1037/0012-1649.22.4.521

Brown, J. D. (2012). Understanding the better than average effect: Motives (still) matter. Personality and Social Psychology Bulletin, 38, 209-219. doi: 10.1177/0146167211432763

Bru, E. (2006). Factors associated with disruptive behaviour in the classroom. Scandinavian Journal of Educational Research, 50, 23-43. doi: 10.1080/00313830500372000

Burgaz, B., \& Ekinci, C. E. (2007). Misbehaviors of high school students and perceptions on the disturbance levels of these misbehaviours. World Applied Sciences Journal, 2, 759769.

Buyse, E., Verschueren, K., Doumen, S., van Damme, J., \& Maes, F. (2008). Classroom problem behavior and teacher-child relationships in kindergarten: The moderating role of classroom climate. Journal of School Psychology, 46, 367-391. doi:10.1016/j.jsp.2007.06.009 
Cairns, R. B., Cairns, B. D., \& Neckerman, H. J. (1989). Early school dropout: Configurations and determinants. Child Development, 60, 1437-1452.

Carifio, J. (1994). Sensitive data and student's tendencies to give socially desirable responses. Journal of Alcohol and Drug Education, 39, 74-84.

Coie, J., \& Kupersmidt, J. B. (1983). A behavioral analysis of emerging social status in boy's groups. Child Development, 54, 1400-1461.

Coie, J. D., Dodge, K. A., Terry, R., \& Wright, V. (1991). The role of aggression in peer relations: An analysis of aggression episodes in boys' play groups. Child Development, 62, 812-826. doi: 10.1111/j.1467-8624.1991.tb01571.x

Condry, J. C., \& Condry, S. M. (1976). Sex differences: A study of the eye of the beholder. Child Development, 47, 812-819.

Connor, D. F. (2002). Risk and protective factors in aggression and related behaviours. New York: Guilford Press.

Corsaro, W. A., \& Eder, D. (1990). Children's peer cultures. Annual Review of Sociology, 16, 197-220. doi: 10.1146/annurev.so.16.080190.001213

Crick, N. R., \& Grotpeter, J. K. (1995). Relational aggression, gender, and socialpsychological adjustment. Child Development, 66, 710-722. doi: 10.1111/j.14678624.1995.tb00900.x

Crick, N. R., Bigbee, M., \& Howes, C. (1996). Gender differences in children's normative beliefs about aggression: How do I hurt thee? Let me count the ways. Child Development, 67, 1003-1014. doi: 10.1111/j.1467-8624.1996.tb01779.x

Cuddy, M. E., \& Frame, C. (1991). Comparison of aggressive and nonaggressive boys' selfefficacy and outcome expectancy beliefs. Child Study Journal, 21, 135-152. 
Dishion, T. J., Patterson, G. R., Stoolmiller, M., \& Skinner, M. L. (1991). Family, school and behavioural antecedents to early adolescent involvement with antisocial peers. Developmental Psychology, 27, 172-180. doi: 10.1037/0012-1649.27.1.172

Douglas, J. (1988). Behaviour Problems in Young Children: Assessment and Management, New York: Routledge.

Eagly, A. H., \& Chaiken, S. (1993). The Psychology of Attitudes. United States: Harcourt Brace Jovanovich College Publishers.

Erwin, P. (1995). Friendship and peer relations in children. Chichester: John Wiley \& Sons.

Estell, D. B., Farmer, T. W., Pearl, R., van Acker, R., \& Rodkin, P. C. (2008). Social status and aggressive and disruptive behavior in girls: Individual, group, and classroom influences. Journal of School Psychology, 46, 193-212. doi:10.1016/j.jsp.2007.03.004

Esturgó-Deu M. E., \& Sala-Roca, J. (2010). Disruptive behaviour of students in primary education and emotional intelligence. Teaching and Teacher Education, 26, 830-837. doi:10.1016/j.tate.2009.10.020

Fabrigar, L. R., Wegener, D. T., MacCallum, R. C., \& Strahan E. J. (1999). Evaluating the use of exploratory factor analysis in psychological research. Psychology Methods 4, 272 299. doi: 10.1037/1082-989X.4.3.272

Field, A. (2002). Discovering statistics using SPSS for windows. London: Sage Publications. Ford, T., Edwards, V., Sharkey, S., Ukoumunne, O. C., Byford, S., ... \& Logan, S. (2012). Supporting teachers and children in schools: The effectiveness and cost-effectiveness of the incredible years teacher classroom management programme in primary school children: A cluster randomised control trail, with parallel economic and process evaluations. $B M C$ Public Health, 12, 719-734. doi:10.1186/1471-2458-12-719 
Furman, W., \& Buhrmester, D. (1992). Age and sex differences in perceptions of networks of personal relationships. Child Development, 63, 103-111. doi: 10.1111/j.14678624.1992.tb03599.x

Geen, R. G. (2001). Human Aggression (2 ${ }^{\text {nd }}$ ed.). Buckingham, Philadelphia: Open University Press.

Harrist, A. W., Pettit, G. S., Dodge, K. A., \& Bates, J. E. (1994). Dyadic synchrony in mother-child interaction: Relations with children's subsequent kindergarten adjustment. Family Relations, 43, 417-424.

Hartup, W. W. (1979). The social worlds of childhood. American Psychologists, 34, 944-949.

Hall, N., \& Hayden, C. (2007). Is 'hate crime' a relevant and useful way of conceptualising some forms of school bullying? International Journal on Violence and Schools, 3, 3-24.

Hennessy, E., Swords, L., \& Heary, C. (2008). Children's understanding of psychological problems displayed by their peers: A review of the literature. Child: Care, Health and Development, 34, 4-9. doi:10.1111/j.1365-2214.2007.00772.x.

Huesmann, L. R., \& Guerra, N. G. (1997). Children's normative beliefs about aggression and aggressive behaviour. Journal of Personality and Social Psychology, 72, 408-419.

Humphrey, N., Lendrum, A., \& Wigelsworth, M. (2010). Social and emotional aspects of learning (SEAL) programme in secondary schools: National evaluation. Available at: https://www.gov.uk/government/uploads/system/uploads/attachment_data/file/181718/DF E-RR049.pdf

Hymel, S., Comfort, C., Schonert-Reichl, K., \& McDougall, P. (1996). Academic failure and school dropout: The influence of peers. In K. Wentzel \& J. Juvonen (Eds.), Social motivation: Understanding children's school adjustment (pp.313-345). New York: Cambridge University Press. 
Juvonen, J. (1991). Deviance, perceived responsibility, and negative peer reactions. Developmental Psychology, 27, 672-681. doi: 10.1037/0012-1649.27.4.672

Kramer, E., Davies, S. C., Arndt, K. J., \& Hunley, S. (2012). A comparison of the mystery motivator and the get 'em on task interventions for off-task behaviors. Psychology in the Schools, 49, 163-175. doi: 10.1002/pits.20627

Kokkinos, C., Panayiotou, G., \& Davazoglou, A. (2004). Perceived seriousness of pupil's undesirable behaviours: The student teachers' Perspective. Educational Psychology, 24, 109-120. doi: 10.1080/0144341032000146458

Lagerspetz, K. M., Bjőrkqvist, K., \& Peltonen, T. (1988). Is indirect aggression typical of females: Gender differences in aggressiveness in 11- to 12-year-old children. Aggressive Behaviour, 14, 403-414. doi: 10.1002/1098-2337(1988)14:6<403::AIDAB2480140602>3.0.CO;2-D

Lahat, A., Helwig, C. C., \& Zelazo, P. D. (2012). Age-related changes in cognitive processing of moral and social conventional violations. Cognitive Development, 27, 181-194. doi: 10.1016/j.cogdev.2012.02.002

Lahey, B. B., Miller, T. I., Gordon, R. A., \& Riley, A. W. (1999). Developmental epidemiology of the disruptive behaviour. In H. C. Quay \& A. E. Hogan (Eds.), Handbook of disruptive behaviour disorders (pp.23-48). New York: Kluwer Academic/Plenum Publishers.

Laird, R. D., Pettit, G. S., Dodge, K. A., \& Bates, J. E. (1999). Best friendships, group relationships, and antisocial behaviour in early adolescence. Journal of Early Adolescence, 19, 413-437. doi: 10.1177/0272431699019004001

Little, T. D., Henrich, C. C., Jones, S. M., \& Hawley, P. H. (2003) Disentangling the "whys" from the "whats" of aggressive behaviour. International Journal of Behaviour and Development, 27, 122-133. doi: 10.1080/01650250244000128 
Loeber, R. (1990). Development and risk factors of juvenile antisocial behaviour and delinquency. Clinical Psychology Review, 10, 1-41.

Loeber, R., \& Dishion, T. (1983). Early predictors of male delinquency: A review. Psychological Bulletin, 94, 68-99.

Loeber, R., \& Keenan, K. (1994). Interaction between conduct disorder and its comorbid conditions: Effects of age and gender. Clinical Psychology Review, 14, 497-523.

Loeber, R., \& Stouthamer-Loeber, M. (1998). Development of juvenile aggression and violence. Some common misconceptions and controversies. American Psychologist, 53, 242-259.

Luteijn, E., Luteijn, F., Jackson, S., Volkmar, F. \& Minderaa, R. (2000). The children's social behaviour questionnaire for milder variants of PDD problems: Evaluation of the psychometric characteristics. Journal of Autism and Developmental Disorders, 30, 317 330.

Mitchell, M. M., Bradshaw, C. P., \& Leaf, P. J. (2010). Student and teacher perceptions of school climate: A multilevel exploration of patterns of discrepancy. Journal of School Health, 80, 271-279. doi: 10.1111/j.1746-1561.2010.00501.x

Offord, D. R., Boyle, M. H., Fleming, J. E., Blum, H. M., \& Grant, N. I. R. (1989). Ontario child health study: Summary of selected results. Canadian Journal of Psychiatry, 34, 483491.

Otero López, J. M., Santiago, M. J., Godás, A., Castro, C., Villardefrancos, E., \& Ponte, D. (2008). An integrative approach to burnout in secondary school teachers: Examining the role of student disruptive behaviour and disciplinary issues. International Journal of Psychology and Psychological Therapy, 8, 259-270. 
Patterson, G. R., Reid, J. B., Jones, R. R. \& Conger, R. E. (Eds.). (1975). A social learning approach to family intervention: Vol 1. Families with aggressive children. Eugene, OR: Castalia.

Patterson, C. J., Vaden, N. A., Griesler, P. C., \& Kupersmidt, J. B. (1991). Income level, gender, ethnicity, and household composition as predictors of children's peer companionship outside of school. Journal of Applied Developmental Psychology, 12, 447465. doi: 10.1016/0193-3973(91)90020-5

Perry, D. G., Perry, L. C., \& Rasmussen, P. (1986). Cognitive social learning mediators of aggression. Child Development, 57, 700-711.

Poulin, F., \& Boivin, M. (2000). Reactive and proactive aggression: Evidence of a two-factor model. Psychological Assessment, 12, 115-122. doi: 10.1037//1040-3590.12.2.115

Rubin, K., Bukowski, W., \& Parker, J. (1998). Peer interaction, relationships and groups. In W. Damon (Series Ed.) \& N. Eisenberg, (Vol. Ed.), Handbook of Child Psychology: Vol 3, Social, emotional, and personality development (pp.619-700). New York: Wiley.

Rust, J., \& Golombok, S. (Eds.). (1999). Modern psychometrics: The science of psychological assessment. London: Routledge, Taylor \& Francis.

Rutter, M., \& Taylor, E. A. (2001). Research and Innovation on the Road to modern child psychiatry. Glasgow: Bell \& Bain Limited.

Slaby, R. G., \& Guerra, N. G. (1988). Cognitive mediators of aggression in adolescent offenders: II. Intervention. Developmental Psychology, 26, 269-277. doi: 10.1037/00121649.26.2.269

Smith, P. K., \& Hart, C. H. (Eds.). (2002). Blackwell handbook of childhood social development. Oxford: Blackwell Publishing Ltd. 
Stuart, H. (1994). Teachers' perceptions of student behaviours: A study of NSW secondary teachers' attitudes. Educational Psychology, 14, 217-232. doi: $10.1080 / 0144341940140206$

Swinson, J. (2010). Working with a secondary school to improve social relationships, pupil behaviour, motivation and learning. Pastoral Care in Education: An International Journal of Personal, Social and Emotional Development, 28, 181-194. doi:

$10.1080 / 02643944.2010 .504221$

Tabachnick, B. G., \& Fidell, L. S. (2001). Using multivariate statistics (4 ${ }^{\text {th }}$ ed). Boston: Allyn and Bacon.

Thelen, E., \& Smith, L. B. (1998). Dynamic systems theories. In W. Damon (Series Ed.) \& R. M. Lerner (Vol. Ed.), Handbook of child psychology: Vol. 1. Theoretical models of human development (pp. 563-634). New York: Wiley.

Tremblay, R. E., Loeber, R., Gagnon, C., Charlebois, P., Larivée, S., \& LeBlanc, M. (1991). Disruptive boys with stable and unstable high fighting behaviour patterns during junior elementary school. Journal of Abnormal Child Psychology, 19, 285-300. doi: 10.1007/BF00911232

Tremblay, R. E., Pihl, R. O., Vitaro, F., \& Dobkin, P. L. (1994). Predicting early onset of male antisocial behaviour from preschool behaviour. Archives of General Psychiatry, 51, 732-739. doi:10.1001/archpsyc.1994.03950090064009

Tremblay, R. E. (2010). Developmental origins of disruptive behaviour problems: The 'original sin' hypothesis, epigenetics and their consequences for prevention. Journal of Child Psychology and Psychiatry, 51, 341-367. doi:10.1111/j.1469-7610.2010.02211.x

Veenstra, R., Lindenberg, S., Oldehinkel, A. J., De Winter, A. F., Verhulst, F. C., \& Johan Ormel, J. (2008). Prosocial and antisocial behaviour in preadolescence: Teachers' and 
parents' perceptions of the behaviour of girls and boys. International Journal of Behavioural Development, 32, 243-251. doi: 10.1177/0165025408089274

Warden, D., Cheyne, B., Christie, D., Fitzpatrick, H., \& Reid, K. (2003). Assessing children's perceptions of prosocial and antisocial peer behaviour. Educational Psychology, 23, 547567. doi: 10.1080/0144341032000123796

Waschbusch, D. A., Porter, S. C., Normand, K. S., Omar, R. K. A., \& D'Amico, D. A. (2004). Investigation of the heterogeneity of disruptive behaviour in elementary-age children. Canadian Journal of Behavioural Science, 36, 97-112. doi: 10.1037/h0087221 
Table 1

The pattern matrixes from the exploratory factor analyses

\begin{tabular}{|c|c|c|c|c|c|c|c|c|c|c|}
\hline \multirow[b]{3}{*}{ Items } & \multicolumn{5}{|c|}{ Self-perceptions } & \multicolumn{5}{|c|}{ Peer perceptions } \\
\hline & \multicolumn{3}{|c|}{ Factor } & \multirow[b]{2}{*}{$M$} & \multirow[b]{2}{*}{$S D$} & \multicolumn{3}{|c|}{ Factor } & \multirow[b]{2}{*}{$M$} & \multirow[b]{2}{*}{$S D$} \\
\hline & IB & NB & $\mathrm{EE}$ & & & IB & NB & $\mathrm{EE}$ & & \\
\hline \multicolumn{11}{|l|}{ Imprudent behaviours (IB) } \\
\hline $\begin{array}{l}\text { Careless and untidy in } \\
\text { school work }\end{array}$ & .61 & .01 & .11 & 2.53 & .99 & .59 & .16 & .07 & 2.37 & 1.13 \\
\hline $\begin{array}{l}\text { Does not bring school } \\
\text { books and pens for class }\end{array}$ & .66 & .93 & .11 & 2.26 & .93 & .62 & .12 & .02 & 2.15 & 1.02 \\
\hline Is dressed untidily & .76 & .05 & .13 & 2.10 & .93 & .78 & .01 & .04 & 2.04 & .99 \\
\hline Lacks concentration & .63 & .03 & .22 & 2.76 & .95 & .66 & .03 & .24 & 2.51 & 1.04 \\
\hline Chats during class & .71 & .02 & .10 & 2.67 & 1.05 & .70 & .01 & .07 & 2.43 & 1.13 \\
\hline Daydreams & .61 & .08 & .21 & 2.26 & 1.04 & .81 & .09 & .05 & 2.16 & 1.12 \\
\hline \multicolumn{11}{|l|}{ Negative behaviours (NB) } \\
\hline Often steals & .03 & .68 & .06 & 3.86 & 1.07 & .06 & .72 & .12 & 3.57 & 1.12 \\
\hline Bullies schoolmates & .09 & .84 & .07 & 4.31 & .96 & .09 & .77 & .15 & 3.91 & 1.06 \\
\hline $\begin{array}{l}\text { Damages school } \\
\text { belongings }\end{array}$ & .10 & .74 & .03 & 3.71 & 1.10 & .12 & .75 & .03 & 3.40 & 1.15 \\
\hline Does not turn up to class & .18 & .48 & .01 & 3.16 & 1.19 & .25 & .57 & .09 & 3.07 & 1.30 \\
\hline $\begin{array}{l}\text { Hurts the teacher through } \\
\text { words of physical actions }\end{array}$ & .02 & .81 & .04 & 4.51 & .94 & .03 & .72 & .00 & 4.19 & 1.06 \\
\hline \multicolumn{11}{|l|}{ Expressed emotions (EE) } \\
\hline Appears sad or unhappy & .03 & .12 & .55 & 2.84 & 1.10 & .02 & .18 & .67 & 2.70 & 1.09 \\
\hline $\begin{array}{l}\text { Cries and feels easily let } \\
\text { down }\end{array}$ & .06 & .07 & .59 & 2.92 & 1.10 & .13 & .13 & .59 & 2.71 & 1.22 \\
\hline Is afraid & .09 & .06 & .83 & 2.86 & 1.14 & .00 & .02 & .87 & 2.68 & 1.14 \\
\hline Is scared & .02 & .01 & .79 & 3.03 & 1.02 & .03 & .00 & .88 & 2.77 & 1.20 \\
\hline Is sensitive & .26 & .10 & .63 & 3.86 & 1.07 & .30 & .07 & .62 & 2.37 & 1.46 \\
\hline
\end{tabular}

Note: Extraction method is principal axis factor and rotation method is oblimin. Rotation converged in 7 iterations 
Table 2

Associations among the perceptions of seriousness of disruptive classroom behaviours, social behaviour, and social desirability controlling for age.

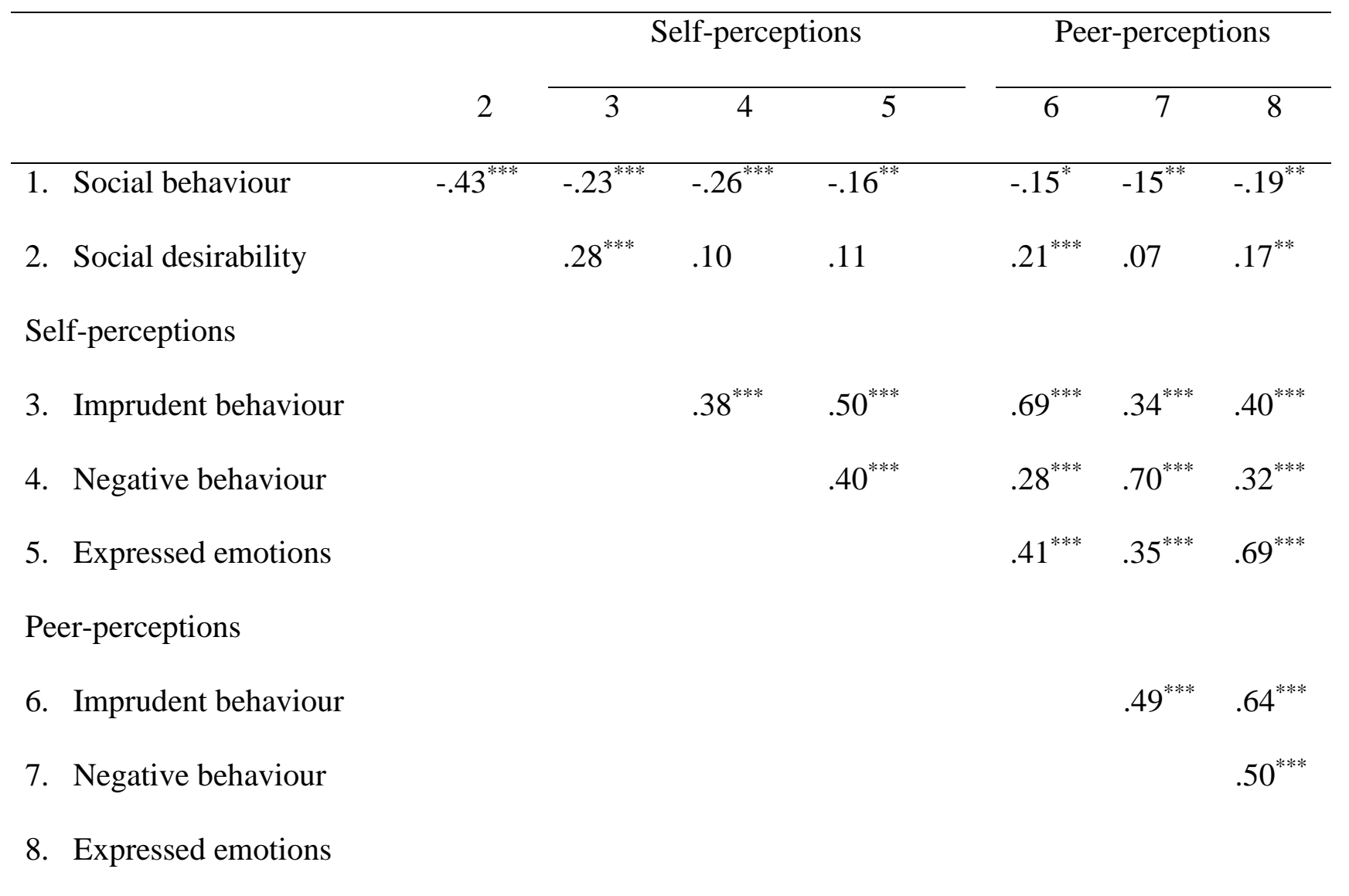

Note. $\mathrm{df}=272$

${ }^{*} p<.05,{ }^{* *} p \leq .01,{ }^{* * *} p \leq .001$ 